$$
\text { DOE }|B C|+4983 \cdots 11
$$

\title{
RECOVERY OF BYPASSED OIL IN THE DUNDEE FORMATION USING HORIZONTAL DRAINS
}

Cooperative Agreement No.: DE-FC22-94BC14983

Contractor Name and Address: Michigan Technological University, 1400 Townsend

Drive, Houghton, MI 49931-1295

Date of Report: 31 October 1996

Award Date: 28 April 1994

Man 2009

Anticipated Completion Date: 27 April 1997

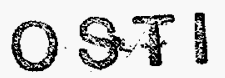

Government Award for Current Fiscal Year: $\$ 800,000$.

Principal Investigator: James R. Wood (906) 487-2894

Project Manager: Chandra Nautiyal, Bartlesville Project Office (918) 337-4418

Reporting Period: July 1, 1996 - September 30, 1996

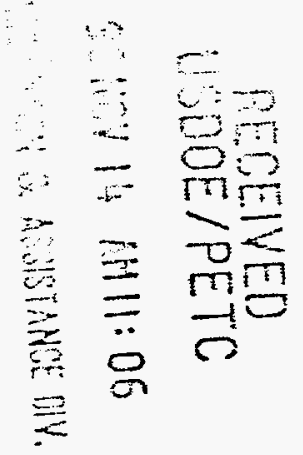

\section{OBJECTIVE}

The principal objective of this project is to demonstrate the feasibility and economic success of producing oil from abandoned or nearly abandoned fields in the Dundee Formation of Central Michigan using horizontal drilling technology.

A site for a horizontal well was selected in Crystal Field, a nearly-abandoned Dundee oil field in Michigan. This field had produced over 8 million barrels of oil, mostly in the 1930's and 1940's. At the height of development, Crystal Field produced from 193 wells, but by 1995 , only seven producing wells remained, each producing less than $10 \mathrm{bbls} /$ day. A horizontal well was drilled as a field demonstration pilot, funded through this DOE project, and was immensely successful. Core and logs from the Dundee interval were recovered from a vertical borehole at the same surface location. The horizontal well was brought on production at a rate of $100 \mathrm{bbls} /$ day and is probably capable of producing at a higher rate. The addition of several horizontal wells, similar to the demonstration well, will likely add another 2 million bbls (or more) to the cumulative production of the field over the next few years. The presence of untapped oil in this Dundee field was 


\section{DECCLAMMER}

Portions of this document may be illegible in electronic image products. Images are produced from the best available original document. 


\section{DISCLAIMER}

This report was prepared as an account of work sponsored by an agency of the United States Government. Neither the United States Government nor any agency thereof, nor any of their employees, make any warranty, express or implied, or assumes any legal liability or responsibility for the accuracy, completeness, or usefulness of any information, apparatus, product, or process disclosed, or represents that its use would not infringe privately owned rights. Reference herein to any specific commercial product, process, or service by trade name, trademark, manufacturer, or otherwise does not necessarily constitute or imply its endorsement, recommendation, or favoring by the United States Government or any agency thereof. The views and opinions of anthors expressed herein do not necessarily state or reflect those of the United States Government or any agency thereof. 
dramatically demonstrated and the favorable economics were made clearly evident. If other abandoned Dundee fields are re-developed in a similar manner, the additional oil produced could exceed 80 million barrels. Horizontal drilling will likely revolutionize the development of old carbonate fields such as those in the Dundee of Michigan.

Additional project work comprises characterization of 30 other Dundee fields in Michigan to aid in determining appropriate candidates for development through horizontal drilling. Further quantification of reservoir parameters such as importance of fracturing, fracture density, and irregularity of the dolomitized surface at the top of the reservoir will help in designing the optimal strategy for horizontal drilling.

Technology transfer takes place continuously, through the Michigan Oil Field Research Consortium (MOFRC) and its Newsletter. Reviews in the popular press have helped reach additional audiences. The success of the demonstration well has been recognized by independent operators, who have requested copies of information published the Newsletter, and who have expressed interest in attending workshops which are being planned for this year. The creation of an "Atlas of Michigan Dundee Reservoirs" is planned as a no-cost addition to this project. The Atlas will greatly enhance the capability of small operators in the state to independently explore and develop this neglected resource.

\section{SUMMARY OF TECHNICAL PROGRESS BY TASK}

\section{BUDGET PERIOD 2}

\section{TASK 1 PROJECT MANAGEMENT}

\subsection{COORDINATION}

The management tasks have gone smoothly this quarter. Various subgroups met and worked on subtasks throughout the quarter.

In August and September, J. Allan and M. Luo traveled to Michigan Technological University (MTU) to work on this DOE project with MTU faculty and graduate students. In September, graduate student Deyi Xie joined the project. He is currently working on computer mapping of the Dundee on a state-wide scale. Also in September, Ph.D. candidate A. Wylie passed his oral examination. He continues to work on basin-wide modeling and sequence stratigraphic studies in both the Dundee and the entire Paleozoic section.

In October, J. Wood and W. Pennington from MTU and W. Harrison and graduate student $\mathrm{H}$. Wines from WMU gave a workshop on the TOW 1-3 demonstration well, Crystal Field, at the monthly meeting of the Michigan Oil and Gas Association (MOGA) in 
downstate Michigan (see Subtask 5.4). Various members of the project staff attend the MOGA Meeting each month. It is proving to be a good vehicle for exchanging information with the independent oil industry on horizontal drilling in the Dundee in other Michigan formations.

\subsection{BUDGET AND REPORTS}

M. Gruener and A. Hein are responsible for daily management of the budget and expenditures. A. Hein is responsible for preparation of quarterly financial reports and for distribution of all reports to DOE. J. Allan is responsible for quarterly and annual technical reports.

\section{TASK 2 RESERVOIR CHARACTERIZATION}

During the fall of 1995, the demonstration well for this project, the TOW No. 1-3 well in Crystal Field, was completed in the Dundee. Daily production has varied from about 75 to $120 \mathrm{BOPD}$ since that time. Currently the well is producing at the $100 \mathrm{BOPD}$ level. The water cut remains at $0 \%$ and pressure has been maintained at 1445 psi by an active water drive.

Cronus Development Co. now plans to drill 9 to 12 additional horizontal wells in the Dundee in Crystal Field during the coming year. Cronus plans to drill $1900 \mathrm{ft}$. laterals (horizontal legs) in each well, similar to that originally planned for the TOW No. 1-3 well. However, to prevent lost circulation and blowout in the fractured and vuggy Dundee reservoir, as occurred while drilling the 1-3 well, special drilling technology will be required. Underbalanced drilling, in which the formation is allowed to flow during drilling, will probably be used. Coiled tubing technology, which minimizes timeconsuming trips in and out of the hole, is being considered. The $90 \mathrm{ft}$ lateral in the TOW No. 1-3 well is producing 120 BOPD with no water cut. It is expected that $1900 \mathrm{ft}$ laterals will be capable of much higher water-free production. DOE has awarded MTU a $\$ 20,000$ supplementary grant to perform additional technical evaluation work on one of these upcoming wells.

Apollo Oil and Gas recently drilled a horizontal well to the Dundee Formation in another central Michigan field. The well came in structurally low. As a result, the horizontal wellbore encountered the Dundee at a low oblique angle and followed the soft Bell Shale along the top of the cap limestone for some distance before penetration of the Dundee was achieved. This incident serves to illustrate that careful attention must be given to drilling technique in order to bring in successful horizontal wells.

\subsection{CORE AND LOG ANALYSIS}

A $59.3 \mathrm{ft}$ core was recovered from the top of the Dundee in the TOW No. 1-3 well. W. Harrison described the core and J. Allan and Harrison later sampled. Petrographic, Xray diffraction, and fluid inclusion analyses are being performed on these samples. The well- 
bore diagram and core description log were placed on the WMU Internet Homepage and can be downloaded by anyone with interest in the project. Graduate student $\mathrm{H}$. Wines at WMU completed Xray diffraction analyses of samples from the TOW 1-3 core collected on a foot-by-foot basis during this quarter. She also Xrayed selected core samples of dolomitized Dundee reservoir recovered from other fields in central Michigan. She is currently comparing mineralogical data to thin section petrography and plans to complete her M.S. thesis on the Dundee at the end of this semester.

Haliburton ran 3 consecutive $\log$ suites on the TOW No. 1-3 well, which included: 1) a gamma ray and dual laterolog with microresistivity, 2) a lithodensity log (compensated formation density plus photoelectric factor), and 3) a compensated neutron log. The logs were then correlated with a high degree of confidence and combined. W. Pennington loaded the digital log traces into MTU's GeoGraphix Exploration System's QLA2 log evaluation software module and began evaluation of the logs for porosity and fluid saturations.

During the second quarter of FY 1996, K. Moss and two other staff members from Western Atlas spent two days at MTU discussing the Crystal Field well, logging techniques, and, in particular, use of the Circumferential Borehole Imaging Log (CBIL) with W. Pennington and other faculty and graduate students. We plan to get Western Atlas to run a CBIL log, along with lithology and saturation logs, on one of the upcoming Crystal Field horizontal wells. Since the relative contribution of matrix porosity and fracture porosity to reservoir produceability and storage capacity are still uncertain at this time, it is essential that these logs be run. This is one of the technical tasks that will be funded by our $\$ 20,000$ supplementary grant.

\subsection{DATA MEASUREMENT AND ANALYSIS}

The uppermost Dundee reservoir was cored in the TOW No. 1-3 well. The coring point was in the lowermost Bell Shale, immediately above the Dundee. $59.3 \mathrm{ft}$ of core were recovered out of a possible $60 \mathrm{ft}$. The core was shipped to OMNI Laboratories in Houston where a core gamma ray log was run and the core was photographed under plane and ultraviolet light to reveal sedimentary structures and heterogeneities in oil saturation. Porosity, permeability, and residual fluid saturation analyses were performed on wholecore samples taken at $1 \mathrm{ft}$ intervals. Xray diffraction analyses of core samples were completed during the past quarter.

Twenty nine feet of higher residual oil saturations at the top of the Dundee (3190-3219 ft) in the core indicate significant unrecovered oil. Beneath that, seven feet of lower residual oil saturations (3219-3226 ft) indicate either a transition zone or a swept zone where the oil-water contact moved up as a result of primary oil production. In the water leg below $3226 \mathrm{ft}$, residual oil saturations are $0.0 \%$. W. Pennington has evaluated the log suite in the TOW No. 1-3 well using GeoGraphix' QLA2 log-evaluation module, but to date has been unable to match saturations calculated from logs to saturations measured in core. 
W. Harrison reviewed production data for the 30 project fields and reorganized and replotted it in ways that will provide useful insights into reservoir heterogeneity and past production practices. The first effort concentrated on Isabella Field, where production data are available for individual leases. Production was plotted for 20 -acre boxes in the field and color-coded according to production volume. Production maps constructed at individual time increments reveal changes in the production pattern with time, while the map of total production pinpoints reservoir heterogeneities and "sweet spots" in the field.

During the past quarter, Harrison performed mass balance calculations and estimated OOIP and recovery factors for Crystal Field. He intends to perform similar calculations on all of the other fields in our seven-county study area for which sufficient data are available. When complete, Excel spreadsheets containing the data and calculations will be placed on the WMU Website, where they can be downloaded by those interested in viewing or using them.

Fourier Transform Infrared Spectroscopy (FTRR) - Elemental analyses were completed using the Inductively Coupled Plasma Spectrograph (ICP) at MTU. More problems were experienced in the calibration of FTIR standards. Current efforts concentrate on obtaining better standards. The FTIR work represents the M.S. thesis research of graduate student $\mathrm{N}$. Popko.

\section{TASK 3 DATABASE MANAGEMENT}

The Multimedia Database Management System (MDMS) has been developed in the commercial software package Toolbook. Design and implementation, which were carried out by C. Asiala, are now essentially complete. All data and information are accessible through drop-down menus and hotlinks in a Table of Contents. A tutorial is presented up front to guide users through the MDMS and instruct them on the various ways in which data can be viewed and retrieved. The MDMS will be written to CD ROM at the end of the project. Copies of the CD ROM will be pressed and made available to the public. The CD ROM, which will contain project maps, cross sections, core and production data, interpretations, and nonproprietary log and seismic data, will be the principal project deliverable.

The following information was entered into the MDMS during the last quarter:

- All quarterly and annual reports to DOE

- Well activity and production decline curves for all 30 study fields

- Basinwide maps of Dundee structure, Bougier gravity anomaly, and oil-well locations

- An east-west Devonian cross section through the basin

- Autocad maps for Crystal Field

- Autocad cross sections for Crystal Field

Now that a front end has been developed for inputting Autocad files to the MDMS, maps and cross sections for the 29 other fields will be added during the coming quarter. Core 
data and core photos will soon be added as well. J. Suchoski is working with C. Asiala to make the MDMS accessible on CD ROM through the MTU Home Page.

C. Asiala developed a search engine in Microsoft Access which can be used to retrieve logs from the CD ROM. Any desired log curve can be located using queries and then exported from the CD ROM to temporary Access tables created on the computer's hard drive. Once in the Access tables, log curves can be manipulated or transferred to log evaluation packages such as GeoGraphix' QLA2 or Crocker's Petrolog program for analysis and plotting.

Log digitization software, produced by Neurolog, Inc., was purchased by MTU, along with a 36 in scanner for reading logs into the program. Hundreds of paper copies of Michigan Basin well logs are available to us from the WMU Core Repository and from companies such as Angstrom Precision and Maness Petroleum that have been providing us with data for the project. With this new software, project staff can digitize their own well logs and input them to QLA2 or Terrastation for quantitative analysis. This eliminates the prohibitive expense of having well logs digitized commercially and will be important to the modeling part of our effort, which will require hundred of digitized well logs in order to be successful. Neurolog also provided us with their map-digitization software module. P. Lasco is organizing our log database in preparation for digitization.

\subsection{TOPICAL REPORTS}

W. Harrison has collected reservoir data for the 30 oil fields in our study area and is organizing and reformatting it into tables of reservoir parameters for the Topical Reports required by DOE and for inclusion in our "Atlas of Michigan Dundee Reservoirs" (see Subtask 3.2). As he completes each field, he forwards the data to C. Asiala enters it in a Microsoft Access database, where it will eventually be input to the MDMS and written to CD ROM.

\subsection{DUNDEE ATLAS}

We plan to create an "Atlas of Michigan Dundee Reservoirs". As envisioned, this Atlas will include a regional overview of Dundee stratigraphy and reservoir variability; development history of the trend, including comparisons between different fields; production history, including a discussion of engineering and completion techniques; and a table of important reservoir parameters for use in characterizing the Dundee reservoir in other old fields for which little data are available. The maps and cross sections already prepared during the first phase of this DOE project will serve as the cornerstone of the Atlas. The main body of the Atlas will consist of individual discussions of reservoir geology, engineering practices, and tables of reservoir parameters for each Dundee field. Discussion of the importance of fracturing, fracture density, and irregularity of the dolomitized surface will aid in the design of the optimal strategy for horizontal drilling. This Atlas will undoubtedly enhance the capability of the small operators in the state to independently explore and develop this neglected resource. W. Harrison is working on 
reports for the Atlas. The Michigan Basin Geological Society has expressed interest in publishing it. The Atlas will represent a major project deliverable.

\subsection{PSEUDO-SEISMIC VISUALIZATION}

3-D visualizations of the Michigan Basin have been constructed in MatLab. This commercially available statistics and visualization package is both flexible and powerful and can easily perform both 3-D surface and 3-D volume visualizations. M. Luo loaded the Angstrom database into MatLab and produced a 3-D volume visualization of the basin that shows the thickness and distribution of the Dundee and other key formations. Cross sections can be made through the basin at any desired angle. Figure 1 illustrates the way MatLab can be used to visualize and "slice and dice" a 3-D data cube.

B. Wei is using MatLab to produce "pseudo-seismic" sections from SP and gamma raylogs. Using Wei's program, individual pseudo-seismic logs (log traces whose amplitudes have been color-coded to resemble seismic amplitude traces) can easily be selected from a map-view window and then displayed as well-log or pseudo-seismic cross sections. This capability adds another useful dimension to our visualization capabilities. During the past quarter, efforts focused on basic program development. Wei originally developed the pseudo-seismic program to analyze the Maness well-log data set. He is now rewriting the front end to the program to take in LAS and well-location data so that log data in any form from any area can be input to the program. He has also begun to write a front end that will enable us to input any logs, not just gamma-ray logs, to MatLab.

\section{TASK 4 MODELING}

\subsection{GEOCHEMICAL MODELING}

The geochemical modeling program CHILLER is being used to model fluid-rock interaction. The feasibility of porosity prediction using CHILLER is being investigated. Geochemical mass transfer work using CHILLER is being carried out by J. Suchoski. Two databases are currently being used. The thermodynamic database SOLTHERM contains thermodynamic information on fluid species, gases, and minerals. Over 400 species are contained in the database. The data are valid over a temperature range of $0^{\circ} \mathrm{C}$ to $300^{\circ} \mathrm{C}$. The database OXYBASE is being used for oxygen isotope calculations.

\subsection{BASIN MODELING}

During this quarter, Everham wrote a PC-based FORTRAN program to convert lithologic sample descriptions on driller's' logs to log ASCII standard (LAS) format, in which form they can be input to GeoGraphix' QLA2 log evaluation module. Once in QLA2, they are converted to $\log$ binary standard (LBS) and can then be handled and displayed as graphic lithology logs. Since QLA2 is used as both a log-evaluation and a cross-section construction tool, we now are able to construct facies cross sections in GeoGraphix. All 10,000 driller's' logs in our working database are now convertible to lithology logs. 
GeoGraphix, Inc.'s management is quite interested in this work, since at present the GeoGraphix Exploration System does not have the capability of handling facies data. Once the Neurolog software is operating, we plan to digitize the paper copies of wireline logs already in our possession and overlay log traces on the facies cross sections.

Subsurface mapping and stratigraphic interpretation is greatly facilitated by the use of digital data that can be used to generate graphic displays. Graphic displays of lithologic sample descriptions (LSD) obtained from driller's logs constitute a source of information that can be used for several purposes. Among these are the rapid identification of potential inaccuracies in commercially available subsurface databases, identification of subsurface facies changes, and facilitation of sequence stratigraphic interpretations. Generation of pseudologs that contain depth versus lithology information in Log ASCII Standard (LAS) or Log Binary Standard (LBS) format allows use of log analysis software to display information and correlate wells.

The LSD data used in this study are from Aangstrom Precision Corporation's Michigan Basin Oil and Gas Well database. The database contains information on 51,275 wells; 11,472 of those include LSD data. Prior to use, the LSD data must be converted to digital form. This was accomplished utilizing a FORTRAN program written to extract the depth and dominant lithology from the database and to then output an LAS file containing the well header information and depth versus lithology data. The program assigns a value of one to the dominant lithology for each depth interval and zero to the other possible lithologies. The current version of the program recognizes ten different lithologies: those most frequently occurring in the basin. The LAS file is then converted to an LBS file using GeoGraphix-Schlumberger's QLA 2 Log Interpretation program. QLA 2 is also used to create a template to display the lithology data. Other templates were made to display the lithology data in association with standard well logs, e.g. gamma ray and neutron density (Fig. 2). The log display templates are used in conjunction with GeoGraphix's Cross Section and WellBase modules to create the PseudoLog lithologic cross-sections. The inclusion of the formation top subsea picks from the database provide a simple, graphic display of the data. Examples from the Michigan Basin demonstrate that the display of data in a graphical fashion provides the user with a visual method to compare top subsea picks to log and lithology data. Potentially incorrect top picks can easily be identified using this method, and the database information corrected. Regional cross-sections made using these data define large-scale sediment patterns and permit identification of stratigraphic sequences with a greater degree of confidence.

The facies plotting capability that we have achieved in GeoGraphix will enable graduate students to do sequence stratigraphic analyses of the Michigan Basin on any scale that they choose. A. Wylie plans to do a sequence stratigraphic study for his doctoral dissertation. During the last quarter, he plotted all significant penetrations of the Glenwood - Prairie du Chien (Cambrian) interval on a map of the Michigan Basin and constructed three cross section (one north-south and two east-west) through the basin using 38 wells. He is currently working on customizing the Angstrom database for use in sequence stratigraphic and other types of regional stratigraphic analyses. 


\section{TASK 5 TECHNOLOGY TRANSFER}

This task involves the transfer of information and useful products derived from this study to our target audience, the oil industry.

\section{Internet Homepage}

The Dundee Project has its own Homepage on the Internet, which is hot linked to the Geology Department at WMU. It can be reached at:

http://www.wmich.edu/geology/corelab/coreres.htm. Project data and figures are being placed on the Homepage as they become available, and can be downloaded by interested parties.

WMU has set up a server for the Michigan DOE Project as an FTP site. At present, it contains zipped files of 27 map sets which include all Autocad maps generated by the project. Production information and other data will soon be added. The address is FTP://141.218.61.24. Once in the FTP site, the user chooses the "pub" directory and then the "doe" directory. All information in the "doe" directory can be downloaded by the user.

\subsection{MICHIGAN OIL FIELD RESEARCH CONSORTIUM (MOFRC)}

Because of the MOFRC Newsletter and press releases, many people who are interested in horizontal drilling and the development of shallow-shelf carbonate reservoirs, both within the Michigan Basin and in other areas, have contacted project personnel. Several calls were from principal officers of independent oil companies who requested information to help them initiate horizontal drilling programs.

\subsection{REPORTS}

\section{PROFESSIONAL PAPERS AND PRESENTATIONS}

\section{Oil and Gas Journal Paper}

A paper comparing various Michigan Dundee exploration plays and describing the history of the TOW 1-3 demonstration well, its drilling program, core and log data, and production results to date, was published in the Oil and Gas Journal on October 21 and October 28, 1996 as a two-part Exploration feature article. Part 1 was entitled "Horizontal well taps bypassed Dundee oil in Crystal Field, Michigan" and Part 2 was entitled "Horizontal well success spurs more Devonian work in Michigan". Although the paper was long, the OGJ editorial staff chose to publish it unabridged because they considered it to be an important contribution to horizontal drilling strategy and Michigan oil and gas development. The paper is appended to this report as Attachment 1. 


\section{Geological Society of America Annual Meeting}

W. Everham and J. Huntoon presented a paper entitled "Subsurface Databases: Graphical Display and Error Detection for Stratigraphic Interpretation in the Michigan Basin" at the Geological Society of America Annual Meeting in October, 1996. The paper describes Everham's work in preparing graphic displays in GeoGraphix of lithologic sample descriptions obtained from driller's logs (see Subtask 4.2). A copy is appended as Attachment 2.

\subsection{ROM AND MEETINGS}

\subsection{WORKSHOPS}

A Workshop was held at the Michigan Oil and Gas Association's (MOGA) monthly meeting on October 17, 1996 to present the results of this Class 2 Reservoir Project to the Michigan independent oil and gas community. J. Wood and W. Harrison made oral presentations. Two different poster displays were also presented, one by J. Wood and W. Pennington of MTU and a second by $W$. Harrison and $H$. Wines of WMU. The core from the TOW 1-3 well, which has been preserved in wooden boxes, was brought down from MTU and put on display.

More than 40 representatives of the Michigan independent petroleum industry attended. A handout which contained a project overview and information on Crystal Field was distributed. Notebooks containing field maps, production history data, and well statistics were on display and were examined closely by many of the independents. Chandra Nautiyal, our DOE program officer, who encouraged us to hold this Workshop, attended the meeting. 


\section{FIGURES AND ATTACHMENTS}

Figure 1. MatLab 3D visualization display illustrating "slice and dice" capability.

Figure 2. Graphic output of lithologic data from driller's logs prepared in GeoGraphix.

Attachment 1. Reprint of October, 1996 Oil and Gas Journal paper on TOW 1-3 well, Crystal Field.

Attachment 2. October, 1996 Geological Society of America abstract by W. Everham and J. Huntoon entitled "Subsurface Databases: Graphical Display and Error Detection for Stratigraphic Interpretation in the Michigan Basin". 


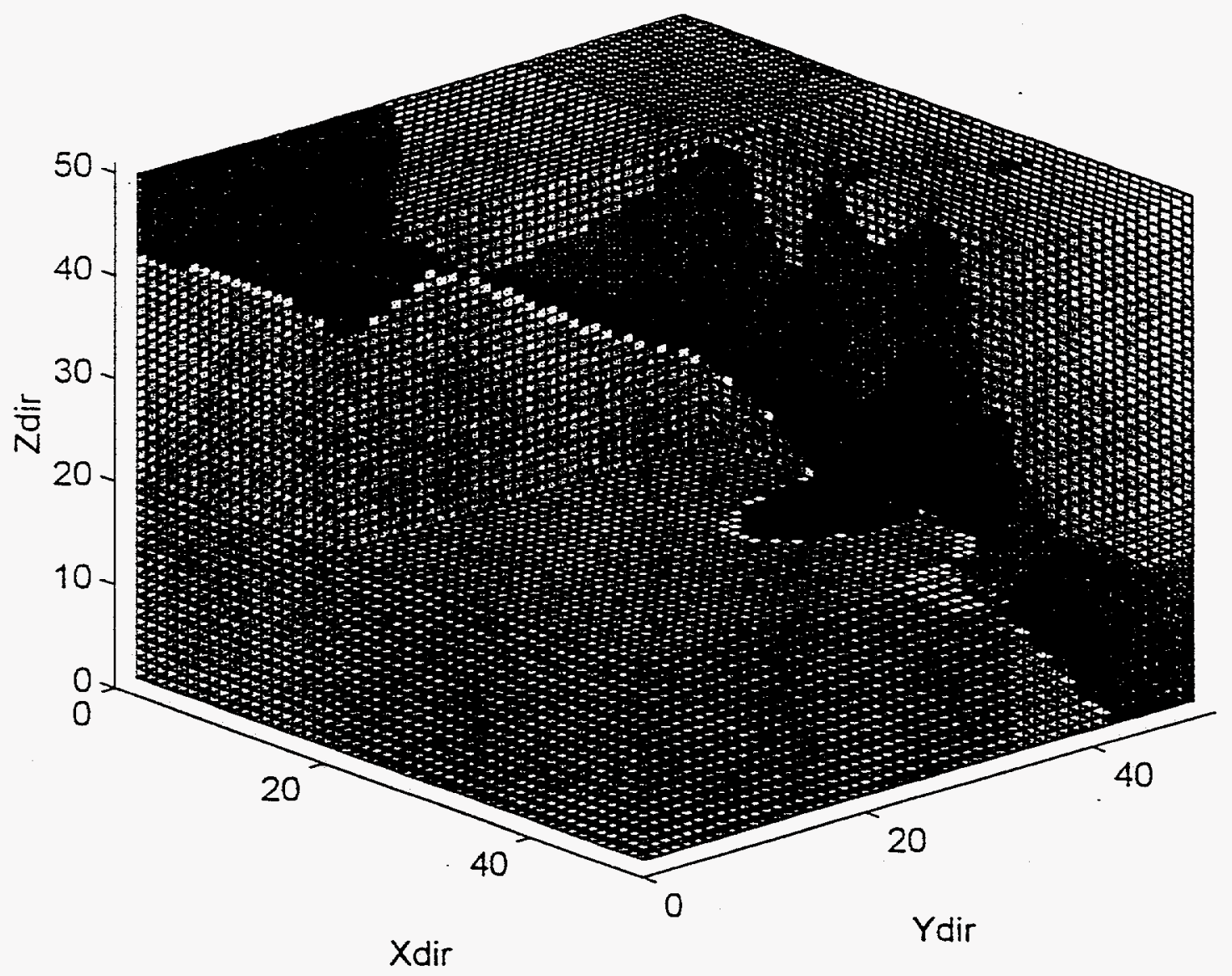

Figure 1 


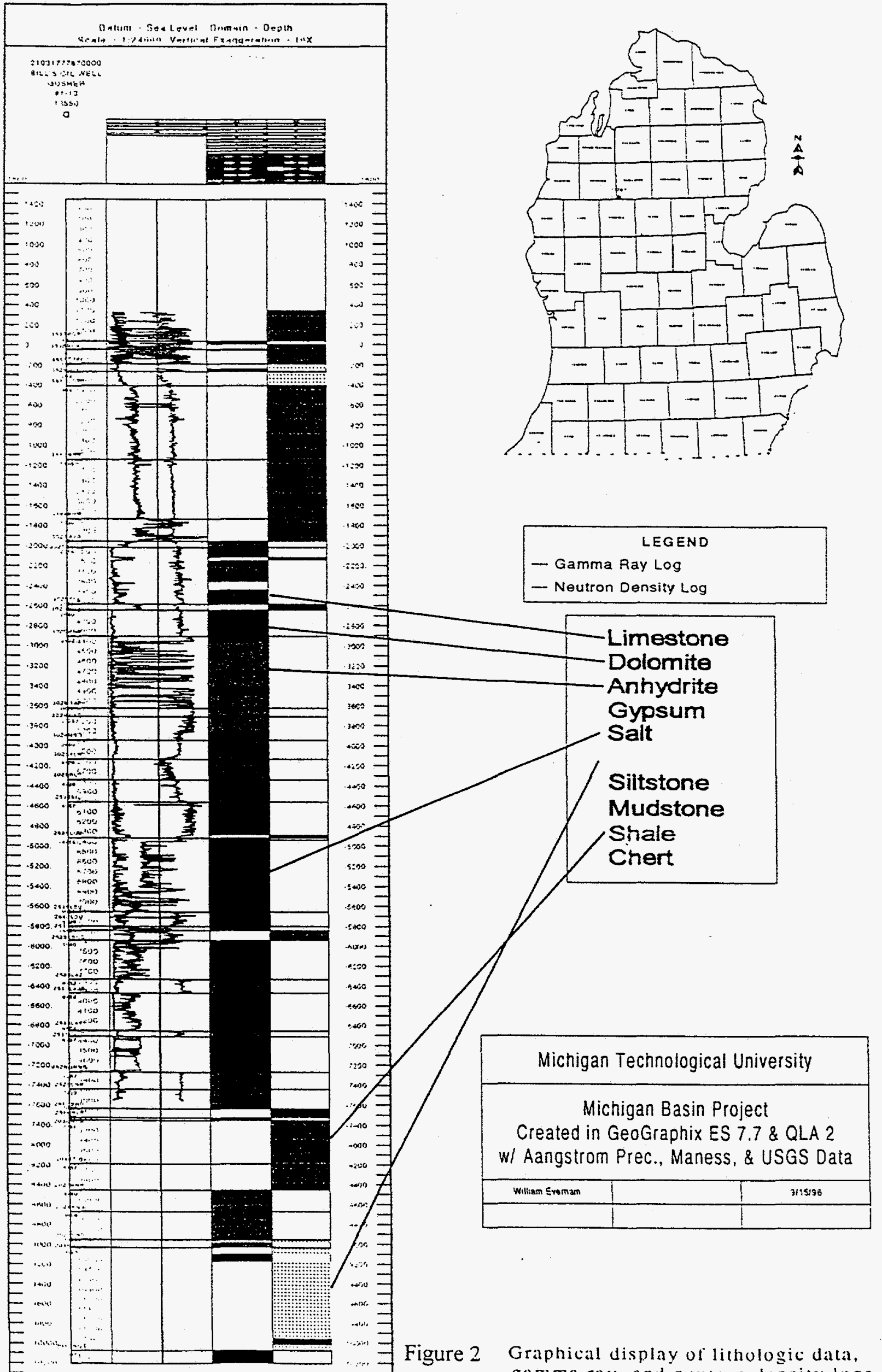

gamma ray, and neutron densicy logs. 
Subsurface Databases: Graphical Display and Error Detection for Stratigraphic Interpretation in the Michigan Basin

EVERHAM, W.D. and HUNTOON, J.E., Dept. of Geol. Eng. and Sci., Michigan Technological University, Houghton, MI 49931, wdeverhalmtu.edu and jehemtu.edu.

Subsurface mapping and stratigraphic interpretation are greatly facilitated by the use of digital data that can be used to generate graphic displays. Graphic displays of lithologic sample descriptions (ISD) obtained from driller's logs constitute a source of information that can be used to rapidly identify potential inaccuracies in commercially available subsurface databases, subsurface facies changes, and display sequence stratigraphic interpretations.

Generation of pseudologs that contain depth vs. lithology information in Log ASCII Standard (LAS) or Log Binary Standard (LBS) format allows use of log analysis software to display information and correlate wells.

Prior to use, ISD data from driller's logs must be converted to digital form. This can be accomplished inhouse or through the purchase of a commercial database. For our study a FORTRAN program was written to extract the LSD data from a commercial database and output the data in LAS format. Commercial log interpretation software was utilized to convert the LAS file to LBS format. A log template was created to graphically display the lithology data. Crosssections that display lithology data and top subsea picks were then generated.

Examples from the Michigan Basin demonstrate that the display of data in a graphical fashion provides the user with a visual method to compare top subsea picks with log and lithology data. Potentially incorrect top picks can be easily identified using this method, and the database information corrected. Regional cross-sections made using these data define large-scale sediment patterns and permit identification of stratigraphic sequences with a greater degree of confidence. 